\title{
Expression of CD44H and CD44v3 in normal oesophagus, Barrett mucosa and oesophageal carcinoma
}

\author{
E Castellà, A Ariza, A Fernández-Vasalo, X Roca, I Ojanguren
}

\begin{abstract}
Aims-To examine CD44H and CD44v3 expression in normal gastric and small bowel mucosa, normal and Barrett oesophagus, and oesophageal epithelial malignancies (squamous cell carcinoma and adenocarcinoma).

Methods-Ninety five specimens, comprised of 40 of normal oesophageal, gastric and small bowel mucosa, 22 of Barrett oesophagus (two with dysplastic changes), 20 of resected adenocarcinomas, and 13 of squamous cell carcinoma, were evaluated. The samples were fixed in formalin and subsequently stained with anti-CD44H and anti-CD44v3 monoclonal antibodies using the avidin-biotin peroxidase technique.

Results-In contrast to normal oesophagus, which showed positivity for both CD44 epitopes (CD44H and CD44v3) in the basal third of the epithelium, antral and intestinal subtypes of Barrett oesophagus expressed CD44H only, the distribution being focal in non-dysplastic and diffuse in dysplastic Barrett mucosa. Similary, normal antral glands and small bowel epithelium were focally immunopositive for CD44H at the base of the crypts. All squamous cell carcinomas were diffusely positive for both isoforms, whereas $75 \%(15 / 20)$ of the adenocarcinomas expressed CD44H and $60 \%(12 / 20)$ expressed CD44v3.
\end{abstract}

Conclusions-CD44H is expressed in the proliferating areas of both normal squamous epithelium and Barrett mucosa. CD44H expression seems to increase progressively in dysplasia and infiltratating carcinoma, similar to the process described in the stomach. CD44v3 expression, usually not observed in normal or neoplastic gastric mucosa, was present in normalsquamous epithelium and oesophageal squamous cell carcinoma. CD44v3 immunoreactivity was also identified in $60 \%$ of adenocarcinomas. These findings suggest that CD44v3 may play a role in the development of oesophageal carcinoma of both squamous and glandular types.

$(\mathcal{F}$ Clin Pathol 1996;49:489-492)

Keywords: oesophageal carcinoma, Barrett mucosa, $\mathrm{CD} 44 \mathrm{H}, \mathrm{CD} 44 \mathrm{v} 3$.
The CD44 cell surface glycoprotein is expressed as multiple isoforms in many normal and neoplastic tissues. ${ }^{1}$ This protein family has been implicated in lymphocyte homing, ${ }^{2}$ cellextracellular matrix interactions, tumour invasiveness, and metastasis. ${ }^{3}$

Differential glycosylation of the extracellular domain of CD44 increases the heterogeneity obtained through alternative splicing. CD44 isoforms modified with glycosaminoglycans such as heparan sulphate contain exon v3. ${ }^{4}$ These modified CD44 isoforms behave as proteoglycan-like substances, and have high affinity for some growth factors, such as heparin binding epidermal growth factor (HBEGF), and could present these growth factors to specific membrane receptors. ${ }^{5} \mathrm{HB}-\mathrm{EGF}$ acts as an autocrine growth factor for human keratinocytes. $^{6}$

The aim of the present study was to evaluate expression of the $\mathrm{CD} 44 \mathrm{H}$ and CD44v3 isoforms in normal and Barrett oesophagus and in the most common oesophageal malignancies, squamous cell carcinoma and adenocarcinoma.

\section{Methods}

Normal and pathological samples of 75 patients (56 men and 19 women; mean age (range) 57 (26-84) years) were retrieved from the archives of the Department of Pathology, Hospital Germans Trias i Pujol. There were 95 samples in total: 22 of Barrett oesophagus (nine antral, six intestinal, two containing dysplastic areas, and seven fundic); 20 of adenocarcinoma (two diffuse and the rest intestinal type); 13 of squamous cell carcinoma; and 10 each of normal oesophageal, fundic, antral, and small bowel musoca obtained from the uninvolved areas of the surgical specimens.

Histological features and prognostic factors were evaluated according to well established criteria. Results obtained with both antibodies in neoplastic samples were correlated with prognostic factors, such as grade of differentiation and evidence of lymph node or visceral metastasis at the time of diagnosis. All biopsy specimens had been fixed in $10 \%$ neutral formalin and embedded in paraffin wax at $57-60^{\circ} \mathrm{C}$.

Sections, $5 \mu \mathrm{m}$ thick, were deparaffinised, placed in methanol containing $0.3 \%$ hydrogen peroxide for 30 minutes at room temperature, washed, heated in a microwave oven $(3 \times$ three minutes with two minute intervals) in buffered citrate (citric acid and sodium citrate, $\mathrm{pH} 6.0$ ), washed, and incubated for 30 minutes with

Department of
Pathology,
Hospital Germans
Trias i Pujol,
Autonomous
University of
Barcelona,
Barcelona, Spain
Correspondence to:
Dr E Castellà,
Department of Pathology,
Hospital Germans Trias i
Pujol,
08916 Badalona, Barcelona,
Spain.
Accepted for publication
20 February 1996




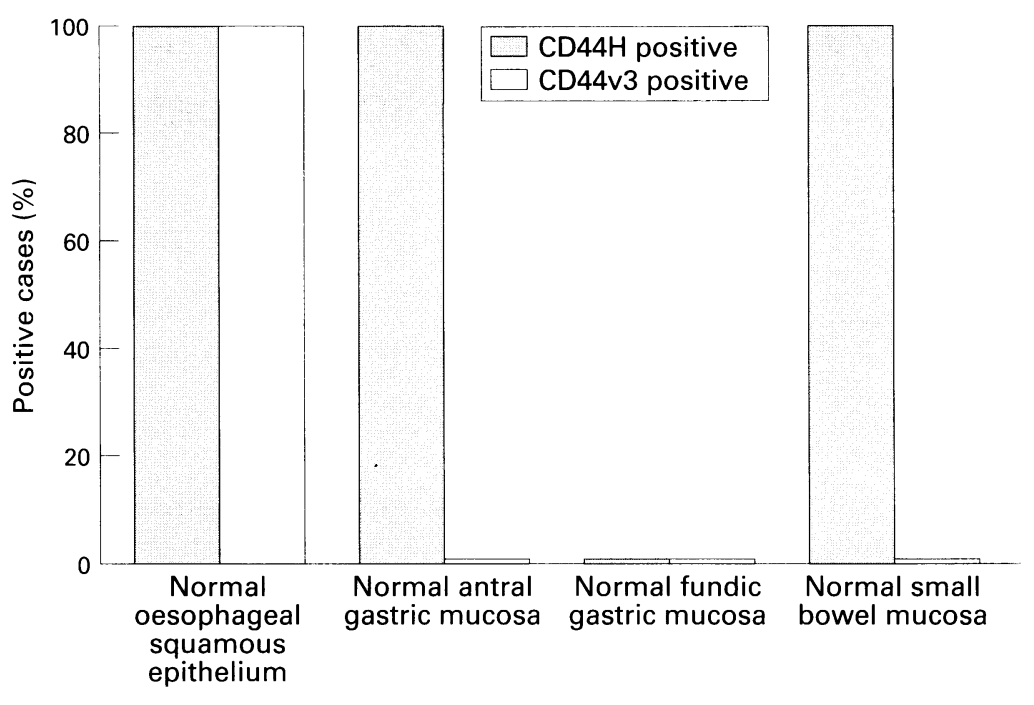

Figure $1 C D 44 H$ and $C D 44 v 3$ expression in normal oesophageal, gastric and small bowel mucosa.

rabbit serum. Sections were then incubated with anti-CD44H (clone 2C5; R\&D Systems, Abingdon, UK) and anti-CD44v3 (clone 3G5; $\mathrm{R} \& \mathrm{D}$ Systems) mouse monoclonal antibodies diluted 1 in 1000 and 1 in 600, respectively, for 22 hours at room temperature. The slides were washed and incubated with biotinylated rabbit anti-mouse immunoglobulin antibodies at a 1 in 700 dilution and with avidin-biotin immunoperoxidase complex (Vector Laboratories, Burlingame, California, USA). 3,3'-diaminobenzidine tetrachloride (Aldrich Chemical Co, Milwaukee, Wisconsin, USA) was used as the chromogen. Sections were counterstained with haematoxylin, dehydrated and mounted (with Permount). A non-immune mouse serum was used in the controls in lieu of the specific monoclonal antibodies.

Two parameters of CD44 expression were examined: (1) the percentage of positively stained cells: negative, $<5 \%$; focal, between 5 and $50 \%$; diffuse, $>50 \%$; and (2) staining intensity: 0 , absent; 1 , weak; 2 , moderate; 3 , strong (comparable with lymphocytes).

Two of the authors examined the slides independently. Those with dissimilar results

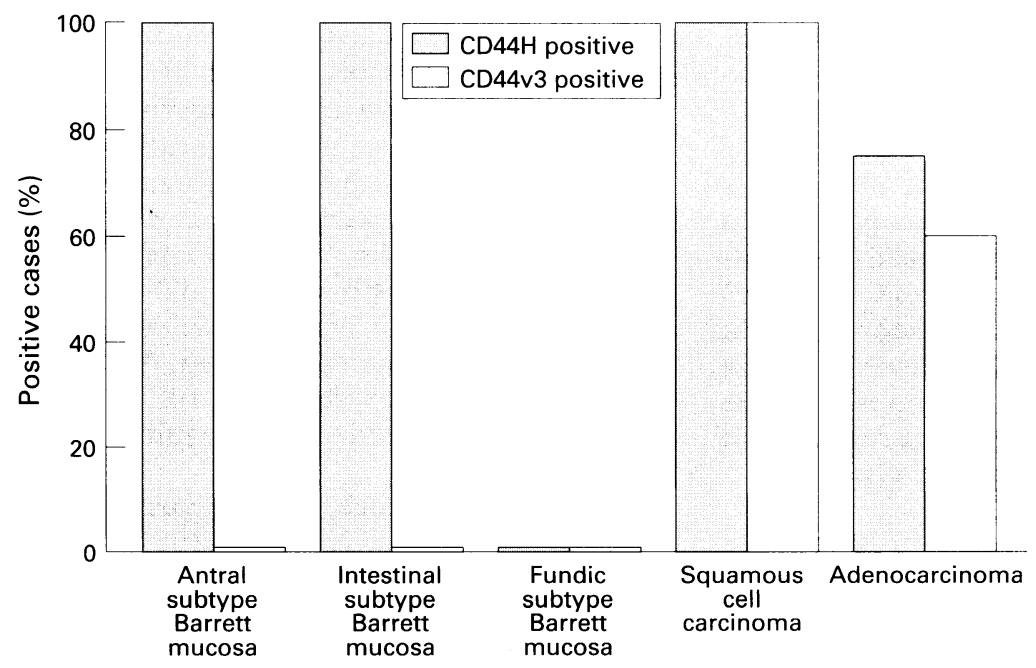

Figure $2 \mathrm{CD} 44 \mathrm{H}$ and CD44v3 expression in Barrett oesophagus, oesophageal squamous cell carcinoma and adenocarcinoma. were reviewed to reach a consensus. Frequency tables were analysed by Fisher's exact test.

\section{Results}

NORMAL OESOPHAGEAL, GASTRIC AND

INTESTINAL MUCOSA

$\mathrm{CD} 44 \mathrm{H}$ was expressed in the basal third of squamous oesophageal epithelium. Control samples of normal gastric and intestinal mucosa showed focal CD44H positivity at the base of the antral and intestinal crypts. Fundic gastric mucosa did not react with either of the antibodies (fig 1).

Endothelial and inflammatory cells (lymphocytes and plasma cells), fibroblasts and smooth muscle cells showed focal immunopositivity for $\mathrm{CD} 44 \mathrm{H}$ in the normal samples studied. CD44v3 was positive only in the basal third of squamous epithelium and smooth muscle cells.

\section{BARRETT OESOPHAGUS}

$\mathrm{CD} 44 \mathrm{H}$ was detected in all of the cases of antral and intestinal subtypes of Barrett mucosa. Fundic type Barrett mucosa was always negative (fig 2). Staining was always focal, except for two cases, both of intestinal subtype with dysplastic areas, which stained diffusely. Staining intensity ranged from weak to strong. None of the Barrett mucosa samples reacted with anti-CD44v3 (fig 2).

\section{ADENOCARCINOMA}

$\mathrm{CD} 44 \mathrm{H}$ was positive in $15(75 \%)$ of the 20 samples studied. Immunostaining was focal in 11 cases and widespread in the other four. Staining intensity was moderate to strong in most cases $(17 / 20,85 \%)$.

CD44v3 was expressed in $60 \%(12 / 20)$ of cases of adenocarcinoma (fig 2), most of which (66\%) showed diffuse immunostaining (fig 3 ). Staining intensity was weak in $58 \%$ of cases and moderate in $33 \%$.

SQUAMOUS CELL CARCINOMA

Diffuse, moderate to strong staining for $\mathrm{CD} 44 \mathrm{H}$ (fig 4) and CD44v3 (fig 5) was observed in all cases.

We did not find any statistically significant correlation between expression of $\mathrm{CD} 44 \mathrm{H}$ and CD 44v3 and the grade or stage of the neoplasms examined.

\section{Discussion}

The most common neoplasms of the lower oesophagus are squamous cell carcinomas and

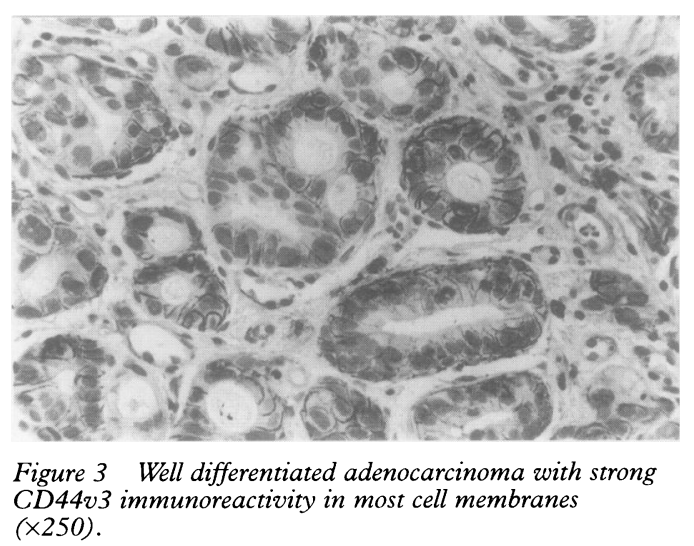




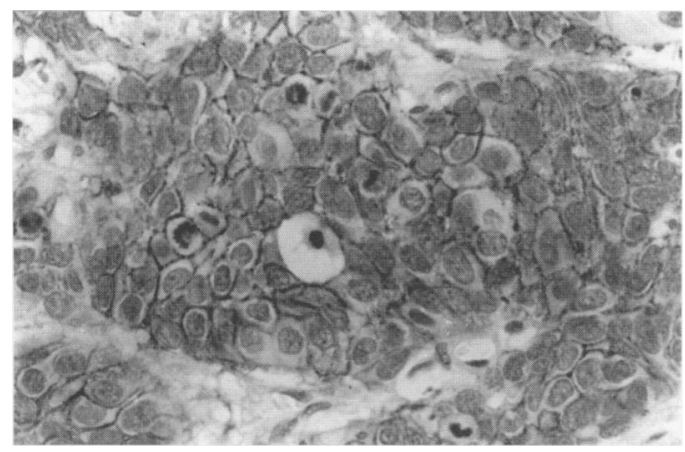

Figure 4 Squamous cell carcinoma with immunoreactivity for CD44H (×250).

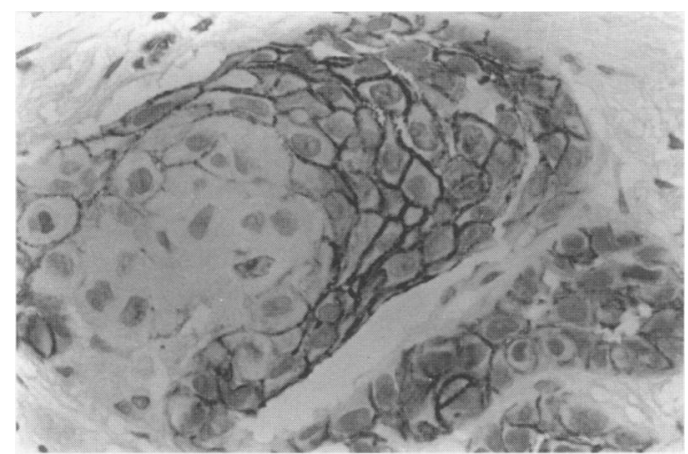

Figure 5 Squamous cell carcinoma with strong CD44v3 immunoreactivity in most cell membranes $(\times 400)$.

adenocarcinomas. The latter account for 10 $28 \%$ of all oesophageal carcinomas, ${ }^{78}$ arise in most cases from Barrett oesophagus (often with dysplastic foci), ${ }^{9}$ and show the same histological variants as gastric adenocarcinoma (intestinal and diffuse).$^{10}$ Histologically, three types of metaplastic columnar epithelium may be seen in Barrett oesophagus: an antral type similar to normal cardial or antral mucosa, a fundic type resembling fundic mucosa, and an intestinal type (so-called specialised type) similar to normal small bowel mucosa.

CD44 is encoded by a gene comprised of 20 exons located on the short arm of chromosome 11. Ten of these 20 exons are always expressed $(\mathrm{CD} 44 \mathrm{H})$. Nine of the other 10 undergo alternative splicing, thereby generating the CD44 isoforms. ${ }^{11}$ Splice variants carrying sequences encoded by exon v6 are expressed preferentially in metastatic animal cancer cell lines. ${ }^{12}$

Immunohistochemical studies have demonstrated differential expression of CD44 epitopes in normal and tumour tissues of the digestive tract. CD44H expression is limited and located at the base of the crypts in normal colonic epithelium, while tumour progression is strongly related to overexpression of CD44H and CD44 isoforms carrying v6 epitopes. Focal expression of v6 in adenomas has also been identified and correlated with tumour progression. ${ }^{13}$ Moreover, expression of $\mathrm{v} 6$ in colon carcinomas correlates with Dukes' stage and seems to be associated with tumour related death. ${ }^{14-16}$

In the stomach, CD44H immunoexpression has been observed in surface epithelium, foveolar proliferation zones and areas of intestinal metaplasia. $\mathrm{CD} 44 \mathrm{H}$ is also expressed irregularly in adenocarcinomas. ${ }^{17}$ Intestinal type adenocarcinoma expresses epitopes encoded by exons v5 and v6, whereas the diffuse type predominantly expresses v5 encoded epitopes. ${ }^{18-20}$ Expression of CD $44 \mathrm{H}$ and several variant isoforms (v3-v6, v8 and v9) has been described in normal oesophageal mucosa. ${ }^{21}$

The diversity of the $\mathrm{CD} 44 \mathrm{H}$ glycoprotein family obtained by means of alternative splicing is further increased by the differential use of numerous $\mathrm{N}$-linked and $\mathrm{O}$-linked glycosylation sites. Specifically, CD44 isoforms carrying the $\mathrm{v} 3$ exon are capable of binding heparan sulphate and can act as proteoglycan-like molecules. These proteoglycan-like CD44 isoforms act as reservoirs for growth factors, and have been implicated in recruitment of growth factors at the cell surface and regulation of their action on target cells. Bennett et al ${ }^{5}$ have demonstrated the complexing of HB-EGF and heparan sulphate modified CD44, which suggests a role for CD44 in keratinocyte growth, as $\mathrm{HB}-\mathrm{EGF}$ is a keratinocyte autocrine growth factor. ${ }^{6}$

In the present study CD44H was expressed in the lower third of the squamous epithelium of normal oesophageal mucosa and in oesophageal squamous cell carcinoma. A similar pattern of expression was found in gastric and intestinal non-neoplastic and neoplastic mucosa, Barrett oesophagus and adenocarcinoma.

Expression of CD44v3 has not been found in normal or neoplastic gastric or intestinal mucosa. As in the study by Fox et al $l^{1}$ of stratified squamous epithelia, we have observed CD44v3 immunostaining at the basal third of the oesophageal squamous epithelium. Barrett mucosa did not react with this monoclonal antibody. A strong diffuse pattern was observed in all squamous cell carcinoma samples with this antibody. Surprisingly, oesophageal adenocarcinoma also showed a weak or moderate, focal CD44v3 immunoreaction in $60 \%$ of cases.

As already mentioned, the intense expression of exon $v 3$ in squamous cell carcinoma cases could be related to the autocrine function of HB-EGF in keratinocytes. However, this finding does not seem to be restricted to squamous cells, as a great proportion of adenocarcinomas were CD44v3 positive in the present study. This distribution suggests that HB-EGF may be instrumental in the control of cell proliferation not only in keratinocytes but also in totipotential stem cells of the squamouscolumnar junction, which in turn suggests a putative role for CD44v3 in the development of oesophageal carcinoma of both the squamous and glandular types.

Supported by Fondo de Investigación Sanitaria Grants $94 / 622$ and $95 / 1345$.

1 Hofmann $M$, Wolfang $R$, Zöller $M$, Tölg C, Ponta $H$, Herrlich $\mathrm{P}$, et al. CD44 splice variants confer metastatic behavior in rats: homologous sequences are expressed in human tumor cell lines. Cancer Res 1991;51:5292-7.

2 Picker LJ, Nakache M, Butcher EC. Monoclonal antibodies to human lymphocyte homing receptors define a novel class of adhesion molecules on diverse cell types. $\mathcal{F}$ Cell Biol 1989;109:927-37. 
3 Lesley J, Hyman R, Kinkade PW. CD44 and its interaction with extracellular matrix. Adv Immunol 1993;54:271-335.

4 Jackson DG, Bell JI, Dickinson R, Timans J, Shields J. Proteoglycan forms of the lymphocyte homing receptor CD44 are alternatively spliced variants containing the v3 exon. $\mathcal{f}$ Cell Biol 1995;128:673-85.

5 Bennett KL, Jackson DG, Simon JC, Tanczos E, Peach R, Modrell $\mathrm{B}$, et al. CD44 isoforms containing v3 are responsible for the presentation of heparin-binding growth sible for the presentation of hepar
factor. $\mathcal{f}$ Cell Biol 1995;128:687-98.

6 Hashimoto K, Higashiyama S, Asada H, Hashimura E, Kobayashi T, Sudo K, Nakagawa T, et al. Heparin-binding epidermal growth factor-like growth factor is an autocrine growth factor for human keratinocytes. $\mathcal{F}$ Biol Chem 1994; 269:20060-6

7 Puestow CB, Gillesby WJ, Guynn VL. Cancer of the esophagus. Arch Surg 1955;70:662-71.

8 Levine MS, Caroline D, Thomson J. Adenocarcinoma of the esophagus: Relationship to Barrett mucosa. Radiology 1984;150:305-9.

9 Hamilton SR, Smith RRL. The relationship between columnar epithelial dysplasia and invasive adenocarcinoma arising in

10 Wang HH, Antoniolli DA, Goldman H. Comparative features of esophageal and gastric adenocarcinoma: Recent changes in type and frequency. Hum Pathol 1986;17:482-7.

11 Screaton GR, Bell MV, Jackson DG, Cornelis FB, Gerth U, Bell JI. Genomic structure of the DNA encoding the lymphocyte homing receptor CD44 reveals at least 12 alternatively spliced exons. Proc Natl Acad Sci USA 1992; 89:12160-4.

12 Günthert U, Hofmann M, Rudy W, Reber S, Zöller M, Haubmann I, et al. A new variant of glycoprotein CD44 confers metastatic potential to rat carcinoma cells. Cell confers metastatic
13 Wielenga VJM, Heider KH, Offerhaus GJA, Adolf GR, van der Berg FM, Ponta $\mathrm{H}$, et al. Expression of CD44 varian proteins in human colorectal cancer is related to tumor progression. Cancer Res 1993;53:4754-6.

14 Heider KH, Hofmann M, Hors E, van der Berg F, Ponta $H$ Herrlich $\mathrm{P}$, et al. A human homologue of the rat metastasis associated variant of CD44 is expressed in colorectal carcinoma and adenomatous polyps. F Cell Biol 1993; 120:227-33.

15 MatsumuraY, Tarin D. Significance of CD44 gene products for cancer diagnosis and disease evaluation. Lancet 1992;340:1053-8.

16 Mulder JWR, Kruit PM, Sewenat M, Oosting J, Seldenrijk $\mathrm{CA}$, Weidema WF, et al. Colorectal cancer prognosis and expression of v6-exon-containing CD44 proteins. Lancet 1994;344:1470-2.

17 Washington K, Gottfried MR, Telen MJ. Expression of the cell adhesion molecule CD44 in gastric adenocarcinomas. Hum Pathol 1994;24:1043-9.

18 Heider KH, Dammrich J, Skrock Angel P, Müller Hermelink HK, Vollmers HP, Herrlich $P$, et al. Differential expression of CD44 splice variants in intestinal and diffuse-type human gastric carcinomas and normal gastric mucosa. Cancer Res 1993;53:4197-203.

19 Mayer B, Jauch KW, Güntert U, Figdor CG, Schildberg FW, Funke LI. De-novo expression of CD44 and survival in gastric cancer. Lancet 1993;342:1019-22.

20 Harn HJ, Ho Li, Chang JY, Wu CW, Jiang SY, Lee HS, et al. Differential expression of the human metastasis adhesion molecule CD44 in normal and carcinomatous stomach mucosa of Chinese subjects. Cancer 1995;75:1065-71.

21 Fox SB, Fawcett J, Jackson DG, Collins I, Gatter KC, Harris $\mathrm{AL}$, et al. Normal human tissues, in addition to some tumors, express multiple different CD44 isoforms. Cancer tumors, express multiple 